\title{
TEKNOLOGI NANO DI BIDANG KEDOKTERAN GIGI
}

\section{(NANO TECHNOLOGY IN DENTISTRY)}

\author{
Sefty Aryani Harahap, Sumadhi Sastrodihardjo \\ Departemen Ilmu Material dan Teknologi Kedokteran Gigi \\ Fakultas Kedokteran Gigi, Universitas Sumatera Utara \\ Jl. Alumni No. 2 Kampus USU, Medan 20155 \\ E-mail: drgsefty@gmail.com
}

\begin{abstract}
In recent time nanotechnology develops rapidly in the field of dentistry. The use of this technology will allow many developments in materials science and biotechnology. Nanotechnology develops nanosized particle due to find out better product of dental materials. By using good dental materials will serve better treatment in dentistry. This paper will explain the application, manufacturing and purpose of nanotechnology in dentistry. Nanocomposite, nanoadhesive, nanoionomer, dental implant, nanoimpression material, denture, dentrifice and orthodontic wire are several materials in dentistry that have been using nanotechnology. Nanoparticle synthesis can be performed by using top-down and bottom-up methodes. In conclusion, using nanotechnology will gain better properties of dental materials such as physic (hardness, translusence, flow, etc), mechanic (strength, modulus of elasticity, flexural strength,etc), chemistry (osseointegration) and biologic properties, although there is still controversial disadvantage in using this nanotechnology such as cytotoxicity.
\end{abstract}

Key words: nanotechnology, nanoparticle, dentistry

\begin{abstract}
Abstrak
Akhir-akhir ini teknologi nano semakin berkembang pesat di bidang kedokteran gigi. Penggunaan teknologi ini akan memungkinkan pengembangan ilmu material dan bio-teknologi. Teknologi nano mengembangkan bahan dalam bentuk partikel berukuran nano untuk mendapatkan produk-produk yang lebih baik. Hal ini erat hubungannya dengan perkembangan bahan dan perawatan di kedokteran gigi. Makalah ini akan memaparkan mengenai pengaplikasian teknologi nano, teknologi pemanipulasian serta tujuan penggunaan teknologi nano di bidang kedokteran gigi. Nanokomposit, dental implan, nanoadhesif, bahan cetak nano, gigi tiruan, pasta gigi dan kawat ortodonti merupakan bahan yang telah menggunakan teknologi nano. Sintesa partikel nano dapat diakukan dengan metode top down (fisika) dan metode bottom up (kimia). Sebagai kesimpulan, dengan teknologi nano ini akan diperoleh sifat-sifat bahan yang lebih baik pada sifat fisis (hardness, translusensi, flow), mekanis (strength, modulus of elasticity, strength, khemis (osseointegrasi) dan biologis. Walaupun demikian masih ada keburukan yang masih kontroversi pada penggunaan teknologi nano, misalnya sitotoksisitas.
\end{abstract}

Kata kunci: teknologi nano, nanopartikel, kedokteran gigi

\section{PENDAHULUAN}

Nano material merupakan material atau bahan yang memiliki komponen kurang dari $100 \mathrm{~nm}$ dalam satu dimensi, seperti kelompok atom, grain, $f$ ber dan film dengan ketebalan kurang dari $100 \mathrm{~nm}$. Pada bahan tambal komposit berbasis resin, partikel ditambahkan nanofiller berukuran mulai dari $100 \mathrm{~nm}$ sampai pada ukuran $5 \mathrm{~nm}(0.005 \mu \mathrm{m})$. Partikel nano dan mikrofiller dipergunakan dalam bentuk cluster atau disperse. Setiap komposit resin yang mengandung filler dari kombinasi dua atau lebih ukur- an partikel disebut hybrid. Komposit hybrid mempunyai filler dalam bentuk partikel koloid..$^{1-5}$

Teknologi nano dipergunakan pada bahan-bahan kedokteran gigi seperti bahan tambal komposit, bahan adhesif, bahan cetak, dental implan, kawat ortodonti dan pasta gigi. Penggunaan teknologi ini akan memungkinkan pengembangan ilmu material dan bio-teknologi. Teknologi nano mengembangkan bahan dalam bentuk partikel berukuran nano untuk mendapatkan produk-produk yang lebih baik. Penggunaan nanofiller pada nanokomposit dapat meningkatkan tensile, compressive, impact dan flexural 
strength serta resistensi terhadap abrasi. Pada bahan adhesif yang mempergunakan partikel nano dapat terdispersi dan mampu mencegah aglomerasi. Pada bahan cetak polyvinyl siloxane penggunaan nanofiller meningkatkan flow menjadi lebih baik, peningkatan sifat hidrofilik untuk mendapatkan detail hasil cetakan yang akurat dan pembuatan model yang lebih baik dan semuanya bertujuan dan erat hubungannya dengan meningkatkan perawatan di bidang kedokteran gigi. ${ }^{1-7}$

Dalam makalah ini akan dipaparkan mengenai pengaplikasian teknologi nano, teknik pemanipulasian serta tujuan penggunaan teknologi nano di bidang kedokteran gigi.

\section{APLIKASI TEKNOLOGI NANO DI BIDANG KEDOKTERAN GIGI}

Teknologi nano di kedokteran gigi digunakan dalam bahan tambal dan adhesif, bahan cetak, dental implan, gigi tiruan, pasta gigi, kawat ortodonti, bahan untuk merangsang pertumbuhan tulang, bahan cangkok tulang dan desinfektan. ${ }^{1-7}$

\section{Teknologi Nano Pada Bahan Tambal \\ 1. Resin Komposit}

Teknologi nano pada resin komposit telah dilakukan pada filler jenis bahan tambal ini. Nanofiller yang digunakan adalah partikel silika atau zirkonia dalam bentuk partikel monodisperse nonagregate dan nonaglomerate. Jenis lain adalah nanocluster yang dibuat dengan lightly sintering nanomeric oxides untuk membentuk cluster. Nanocluster merupakan hasil sintesa silika sol seperti dari campuran oksida silika dan zirkonia. Pada saat ini ada dua tipe komposit yang mengandung partikel nano yaitu $n a-$ nofiller yang mengandung partikel berukuran 1-100 $\mathrm{nm}$ di seluruh matriks resin dan nanohibrid yang berisikan partikel yang besar $(0.4-5 \mu \mathrm{m})$ dengan penambahan partikel berukuran nanometer. Resin komposit nanofiller yang sebenarnya hanya terdapat pada kombinasi partikel nanomer dan nanocluster. $2,6,8-10$

Nanomer merupakan sintesa sol membentuk partikel dengan ukuran yang sama yang bila dipergunakan hanya dalam bentuk ini akan menjadikan sifat reologi yang kurang baik. Untuk mengatasi hal ini dapat dipakai bentuk nanocluster yang diperoleh dari lightly sintering oksida nanomerik. Nanocluster diperoleh dari sintesa silika sol seperti juga dari campuran oksida silika dan zirkonia. 2,6,8-10

Partikel nano memungkinkan resin komposit mempunyai permukaan halus setelah proses pemolesan dan menghasilkan sifat estetis yang baik. Hal ini disebabkan nanokomposit memiliki ukuran jauh lebih kecil dan mengandung jumlah bahan pengisi yang jauh lebih banyak. Bahan pengisi nanokomposit memiliki translusensi yang lebih tinggi karena lebih kecil dari panjang gelombang cahaya (400-800nm), yang memungkinkan generasi yang lebih estetis dengan berbagai pilihan warna., ${ }^{2,-10}$

Resin komposit yang mengandung partikel nano tersebut mudah dibentuk dan memiliki kekuatan dan ketahanan yang tinggi terhadap abrasi. Resin komposit dengan nanofiller telah menunjukkan sifat fisik yang lebih baik. Bahan ini mempunyai compressive, tensile, impact dan flexural strength dan resistensi terhadap abrasi yang lebih tinggi dari komposit tradisional yang berisi partikel mikro. ${ }^{2,8-10}$

Penelitian Monfared dkk. menunjukkan peningkatan flexural strength dan microhardness setelah penambahan filler partikel nano kaca. ${ }^{11}$ Chan dkk. melakukan penelitian tentang ketahanan terhadap fraktur dan memperoleh bahwa ketahanan terhadap fraktur meningkat dengan penggunaan partikel nano $\mathrm{ZrO}_{2}$ pada nanokomposit. ${ }^{12}$

Hasil penelitian Permatasari dkk. mengungkapkan bahwa kombinasi nanokomposit metakaolin zirkonia apatit untuk aplikasi restorasi gigi direk dapat menghasilkan hardness yang tinggi dan interaksi yang baik dengan gigi. ${ }^{13} \mathrm{Xia}$ dkk. melaporkan bahwa dengan menambahkan partikel nano titanium oksida $\left(\mathrm{TiO}_{2}\right)$ pada resin komposit dapat meningkatkan microhardness dan flexural strength. ${ }^{14}$

Sejauh ini belum ada informasi mengenai pelepasan nanopartikel dari komposit berbasis resin selama penambalan, carving atau pemolesan dan selama pemakaiannya. ${ }^{1}$ Penelitian Kholidina menunjukkan terlepasnya elemen-elemen karbon (C), silikon ( $\mathrm{Si}$ ), aluminium ( $\mathrm{Al}$ ), dan titanium (Ti) dari resin komposit nanohibrid setelah direndam dalam saliva buatan. ${ }^{15}$

\section{Glass Ionomer}

Bahan ini merupakan Resin Modified Glass Ionomer (RMGI) dimana partikel nano seperti nanomer dan nanocluster ditambahkan pada Fluoroaluminasilikat (FAS) glass. Penambahan partikel nano meningkatkan kemampuan untuk dipoles dan sifat optik dari ionomer. FAS pada bahan ini memiliki luas permukaan yang sangat tinggi sehingga pelepasan fluor tidak terganggu. ${ }^{1,2}$

\section{Teknologi Nano Pada Bahan Adhesif}

Resin semen merupakan bahan komposit berviskositas rendah dengan pendistribusian filler dan kandungan inisiator dibuat sedemikian rupa agar terdapat ketebalan bahan yang yang tidak terlalu tebal dengan waktu kerja dan pengerasan yang se- 
suai. Beberapa bahan adhesif mengandung filler seperti nanofiller. Walaupun kebanyakan bahan bonding tanpa filler, beberapa produk mengandung nanofiler dan submicron glasses sekitar 0,5-40\% berat. Bahan adhesif dengan nanofiller ini akan lebih mudah diaplikasikan pada gigi dan dapat menghasilkan kekuatan bonding yang lebih tinggi secara in vitro. Bahan adhesif dapat mengandung fluor, bahan-bahan antimikrobial atau bahan desensitisasi, seperti glutaraldehida. Efektifitas fluor dan bahan antimikrobial yang dilepaskan oleh bahan bonding belum dapat dijelaskan. ${ }^{1,2,5}$

\section{Teknologi Nano Pada Bahan Cetak}

Teknologi nano dipakai juga pada berbagai bahan cetak seperti alginat dan polyvinyl siloxane. Keuntungan yang diperoleh adalah flow yang lebih baik, peningkatan sifat hidrofilik sehingga terdapat detail hasil cetakan yang lebih akurat dan penuangan model yang lebih baik., $, 5,7,16$

Jafari dkk. melaporkan bahwa nanosilver colloid 1000 ppm yang ditambahkan pada irreversible hydrocolloid alginat dapat menghambat pertumbuhan Staphylococcus aureus. ${ }^{17}$

\section{Teknologi Nano Pada Bahan Implan}

Bahan yang sering digunakan pada dental implan jenis logam adalah titanium. Aplikasi nanokristal bioaktif kalsium fosfat pada permukaan titanium dapat menstimulasi aposisi dan penyembuhan tulang sehingga dapat meningkatkan osseointegrasi. . $^{3,18,19}$

Partikel nano hidroksiapatit dipakai sebagai bahan cangkok tulang yaitu dalam perawatan terhadap cacat tulang, trauma maksilofasial dan cleft yang membutuhkan cangkok tulang. ${ }^{5}$

\section{Teknologi nano pada bahan gigi tiruan}

Penerapan teknologi nano pada penelitan Chladek dkk. dengan menambahkan partikel nano perak sebagai bahan modifikasi soft liner gigi tiruan untuk menghambat pertumbuhan mikroorganisme. Bahan soft liner biasanya digunakan untuk melapisi gigi tiruan untuk mendistribusikan gaya yang diberikan pada jaringan lunak di bawah gigi tiruan selama proses pengunyahan, biasanya digunakan pada pasien dengan alveolar ridge yang tajam, mukosa sedikit atrofi, mukosa normal dengan resorpsi ridge dan jika mukosa menunjukkan toleransi yang rendah terhadap beban yang diberikan oleh gigi tiruan. Penggunaan soft liner dapat memungkinkan pertumbuhan mikroorganisme yang didukung oleh kondisi lingkungan gigi tiruan (kelembaban dan suhu tinggi) serta struktur bahan. ${ }^{20}$

\section{Teknologi Nano Pada Bahan Pasta Gigi}

Teknologi nano pada bahan pasta gigi yaitu dengan menggunakan nanokristal hidroksiapatit. Pasta gigi ini membentuk lapisan pelindung pada enamel gigi dan dapat mengembalikan permukaan gigi yang rusak. $3,5,16$

\section{Teknologi Nano Pada Bahan Kawat Ortodonti}

Teknologi nano pada bahan kawat ortodonti dilakukan pada stainless steel yang memungkinkan mendapatkan strength yang sangat tinggi dengan kesanggupan untuk kembali ke bentuk semula dan ketahanan terhadap korosi yang baik. ${ }^{2,3,5,7}$

\section{Pemanipulasian partikel nano}

Sintesis partikel nano dapat dilakukan dalam fasa padat, cair, maupun gas. Proses sintesis juga dapat berlangsung secara top-down (fisika) ataupun bottom-up (kimia). Top-down (fisika) yaitu dengan memecah partikel besar menjadi partikel berukuran nanometer. Metode-metode yang termasuk dalam top-down, antara lain mechanical milling, repeated quenching dan litoghraphy. Di bidang kedokteran gigi, sintesis partikel nano dengan pendekatan ini digunakan pada pembuatan pasta gigi dan kawat ortodonti. Bottom-up (kimia) yaitu atom-atom atau molekul-molekul yang disusun membentuk partikel berukuran nanometer. Metode-metode yang termasuk bottom-up, antara lain sol gel process, aerosol based process, Chemical Vapour Deposition (CVD), ato-mic condensation, gas phase condensation dan supercritial fluid synthesis. Sintesis partikel nano dengan pendekatan ini digunakan pada pembuatan nanokomposit, nano-solution, bahan cetak dan bahan cangkok tulang. ${ }^{16,21}$

\section{PEMBAHASAN}

Dari uraian di atas terlihat penggunaan teknologi nano di bidang kedokteran gigi banyak memberikan keuntungan. Bahan tambal resin komposit menggunakan partikel nano untuk meningkatkan compressive, tensile, impact dan flexural strength, microhardness dan resistensi terhadap abrasi. Bahan ini juga mempunyai permukaan halus setelah proses pemolesan dan memiliki translusensi yang lebih tinggi dengan berbagai pilihan warna sehingga dapat menghasilkan sifat estetis yang lebih baik. Demikian juga pada penambahan partikel nano pada RMGI 
meningkatkan kemampuan untuk dipoles dan karakteristik optisnya. Bahan adhesif yang mengandung nanofiller lebih mudah ditempatkan pada gigi geligi dan dapat menghasilkan kekuatan bonding yang lebih tinggi secara in vitro. ${ }^{2,5,8-10}$

Pada bahan cetak penggunaan teknologi nano ini menghasilkan sifat flow yang lebih baik, peningkatan sifat hidrofilik sehingga terdapat detail hasil cetakan yang lebih akurat. Rongga mulut mempunyai banyak mikrobiota yang dengan mudah menyebabkan infeksi dan infeksi silang melalui hasil cetakan. Penambahan nanosilver colloid pada bahan cetak alginat dapat menghambat pertumbuhan Staphylococcus aureus, diharapkan dapat mengurangi terjadinya infeksi silang. ${ }^{16,17}$

Keuntungan penggunaan teknologi nano pada dental implan adalah tercapainya osseointegrasi. Osseointegrasi yang baik dipengaruhi oleh komposisi kimia dan geometri atau topografi permukaan. Degradasi lapisan permukaan implan dapat membantu memicu pembentukan tulang baru akibat peningkatan osteokonduktivitas karena perubahan topografi permukaan ataupun peningkatan osteogenesis. Hal ini disebabkan pelepasan kalsium atau unsur-unsur lain secara lokal yang dapat meningkatkan pembentukan tulang. Modifikasi permukaan implan dengan partikel nano dapat meningkatkan migrasi sel-sel mesenkim pada permukaan implan, meningkatkan perlekatan dan proliferasi sel-sel ini, dan, dalam beberapa kasus dapat merangsang differensiasi osteoblas, proses osseointegrasi lebih baik dan lebih cepat. ${ }^{18,19}$

Partikel nano hidroksiapatit dipakai sebagai bahan cangkok tulang yaitu dalam perawatan terhadap cacat tulang, trauma maksilofasial dan cleft yang membutuhkan cangkok tulang. Penggunaan partikel nano perak sebagai bahan modifikasi soft liner gigi tiruan yang dapat mencegah infeksi mukosa dengan cara menghambat mikroorganisme seperti koloni Candida albicans yang tidak hanya di permukaan tetapi juga penetrasi ke dalam bahan soft liner gigi tiruan. Penambahan nanokristal hidroksiapatit pada bahan pasta gigi membentuk lapisan pelindung pada enamel gigi dan memperbaiki permukaan gigi yang rusak. Pada kawat ortodonti stainless steel yang menggunakan teknologi nano dapat meningkatkan kekuatan dengan kemampuan untuk kembali ke bentuk semula dan ketahanan terhadap korosi yang baik. $5,7,20$

Perkembangan teknologi nano kedokteran gigi di masa mendatang akan berkembang pesat dengan adanya interaksi antara biomaterial dan biomolekuler. Pengembangan regenerasi jaringan akan meningkat. Meskipun pada beberapa penelitian ditemukan adanya perubahan morfologi pada sel endotel vaskular karena partikel nano yang berukuran sangat kecil dapat penetrasi ke dalam darah dan pada konsentrasi tinggi dapat merangsang sitotoksisitas, hal ini masih kontroversial dan membutuhkan penelitian lebih lanjut. ${ }^{18,22}$

Perkembangan teknologi nano akan memberikan efek yang besar pada ilmu bahan kedokteran gigi. Sifat bahan pada tingkatan partikel mikro dan makro yang dikenal pada saat sekarang ini akan sangat berbeda pada tingkat nano. Metode biofabrication dan bioprinting akan menciptakan bahan dan struktur baru dengan biokompatibilitas yang baik. 1,3,21,22

Sebagai kesimpulan, teknologi nano sebagai sarana untuk menghasilkan partikel nano memberikan peningkatan kualitas bahan kedokteran gigi dalam menunjang peningkatan perawatan kedokteran gigi.

\section{Daftar Pustaka}

1. Schmalz G, Bindslev DA. Biocompatibility of dental materials. Berlin: Springer, 2009: 99-231.

2. Sakaguchi RL, Powers JM. Craig's restorative dental materials $13^{\text {th }}$ ed., Philadelphia: Elsevier, 2012: 127-89.

3. Ozak ST, Ozkan P. Nanotechnology and dentistry. Eur J Dent 2013; 7(1): 145-51.

4. Rybachuk AV, Chekman IS, Nebesna TY. Nanotechnology and nanoparticles in dentistry. Pharmacol Pharm J 2009; 1: 18-21.

5. Nagpal A, Kaur J, Sharma S, Bansal A, Sachdev P. Nanotechnology-the era of molecular dentistry. Indian J Dent Sci 2011; 3(5): 80-2.

6. Chen MH. Update on dental nanocomposites. J Dent Res 2010; 89(6): 549-60.

7. Singh A, Vivek R. Nanotechnology in dentistryfuture ahead. AJMAMS 2012; 1(1): 1-7.

8. Mitra SB, Wu D, Holmes BN. An application of nanotechnology in advanced dental materials. J American Dent Assoc 2003; 134: 1382-90.

9. Saunders SA. Current practicality of nanotechnology in dentistry. Part 1: Focus on nanocomposite, restoratives and biomimetics. Clinical, cosmetic and Investigational Dentistry 2009; 1: 47-61.

10. Rahman IA, Padavettan V. Synthesis of silica nanoparticles by sol-gel: size-dependent properties, surface modification, and applications in silica-polymer nanocomposites-a review. J Nanomater 2012: 1-15.

11. Monfared M, Mirdamadi S, Khavandi A. Synthesis of new dental nanocomposite with glass nanoparticles. Nanomed J 2014; 1(2): 107-11.

12. Chan KS, Nicolella DP, Furman BR, Wellinghoff ST, Rawls HR, Pratsinis SE. Fracture toughness of zirconia nanoparticle-filled dental composites. J Mater Sci 2009; 44: 6117-24.

13. Permatasari T, Haris BW, Zaini AR, Aufan MR, Purwasasmita BS. Synthesis of Metakaolin-zirconiaapatite nanocomposite for the application of direct teeth restoration. Int J Solid Struct 2012; 1(1): 1-4. 
14. Xia Y, Zhang F, Xie H, Gu N. Nanoparticlereinforced resin-based dental composites. J Dent 2008; 36: 450-5.

15. Kholidina IH. Serapan cairan dan kelarutan elemenelemen bahan restorasi resin komposit mikrohibrid dan nanohibrid setelah direndam di dalam saliva buatan (in vitro). Tesis. Medan: Program Pascasarjana FKG USU, 2013: 76.

16. Kaira LS, Singh R. Nanotechnology : the new era of technology. Nitte Univ J Health Sci 2012; 2(4): 88-92.

17. Jafari A, Bakhtiari R, Shahabi S, Rahman Nia J, Mehrabadi JF, Yousefi B. Antimicrobial activity of irreversible hydrocolloid impression against oral microorganisms. J Basic Appl Sci Res 2013; 3(6): 397-401.
18. Nayar S, Bhuminathan S, Muthuvignesh J. Upsurge of nanotechnology in dentistry and dental implants. Indian J Multidisciplinary Dentistry 2011; 1(5): 264-8.

19. Lavenus S, Louarn G, Layrolle P. Nanotechnology and dental implants. Int J Biomater 2010: 1-9.

20. Chladek G, Rybarek IB, Lukaszczyk J. Developing the procedure of modifying the denture soft liner by silver nanoparticles. Acta Bioeng Biomech 2012; 14(1): 23-9.

21. Abdullah M, Virgus Y, Nirmin, Khairurrijal J. Review: Sintesis Nanomaterial. J Nano Saintek 2008; 1(2): 33-57.

22. Scientific Committee on emerging and newly identified health risk (SCENIHR). Nanotechnologies. Green Facts 2006: 1- 16. 